\title{
The Role of Premenstrual Syndrome in the Causation of Arterial Hypertension in Women
}

\author{
B. N. Okeahialam \\ Cardiology Unit, Department of Medicine, Jos University Teaching Hospital, Jos, Nigeria \\ Email: basokeam@yahoo.com
}

Received 13 July 2014; revised 8 August 2014; accepted 5 September 2014

Copyright (C) 2014 by author and Scientific Research Publishing Inc.

This work is licensed under the Creative Commons Attribution International License (CC BY). http://creativecommons.org/licenses/by/4.0/

(c) (i) Open Access

\section{Abstract}

Introduction: Gender perspectives are gradually generating great interest in health matters. Hypertension is one illness where gender considerations are important. Advancements in knowledge of pathophysiology help in better understanding of diseases and improvements in treatment. Pre-menstrual syndrome has been reported to make hypertension less responsive to treatment. This work was therefore done to see if premenstrual syndrome contributed in some way to hypertension in women. Methodology: All female hypertensives consulting the author in a private specialized hypertension clinic were questioned using the University of Carlifornia at San Diego criteria with a view to determining if they suffered from pre-menstrual syndrome. The control status was also considered for each patient. Females who consulted over the same period and were not hypertensive served as controls. Result: Pre-menstrual syndrome was found to occur more in hypertensive women than normotensive controls; to a statistically significant extent ( $p<$ 0.05). Control tended to be poorer in hypertensives with pre-menstrual syndrome than those without. The difference however did not achieve statistical significance. Discussion: There is controversy surrounding the aetiology of pre-menstrual syndrome. However, each of the models albeit inconsistent is capable of initiating and sustaining hypertension. The result here shows that in women it is likely to be one of the many factors that could produce hypertension in those predisposed. Conclusion: Pre-menstrual syndrome should arouse suspicion of future hypertension, and should be sought in all female hypertensives. Its presence should evoke deliberate action to improve outcome or remove the need for pharmacotherapy, at least for some time.

\section{Keywords}

Pre-Menstrual Syndrome, Hypertension, Women, Cause, Hypothesis 


\section{Introduction}

Gender perspectives in health have continued to generate a lot of interest to the public in general and the medical profession in particular [1]. Hypertension is one such area where gender determines incidence, pathophysiology, treatment and sequelae [2]. Worldwide, optimal control of hypertension is still lagging behind expectation [3]. It is this background that has given rise to advanced studies in pathophysiologic mechanisms of hypertension. The result is increasing understanding of the role played by certain humoral factors (endothelins, natriuretic peptides, adrenomedullins and leptins) in the development of arterial hypertension [4]. Pre-menstrual syndrome (PMS) is a phenomenon which though recognized for decades, has only recently started to attract interest [5]. It occurs worldwide with varying frequencies, the highest being among Nigerian and Turkish women [6]. Even though all aetiological models, inconsistent as they are, are capable of initiating or sustaining arterial hypertension; no clear association between them has been established.

Some time ago, one encountered some women whose hypertension proved difficult to control until their underlying PMS was identified and treated [7]. Experience with them revealed that once PMS was identified and addressed, quality of life improved, and antihypertensive requirement drastically fell. This benefit can only accrue, if history of PMS is sought in hypertensive women. The question then arises as to the role of PMS in female hypertension. Is it a contributory factor or just a state which when co-existent, makes the treatment of hypertension difficult? The aim of the study was to see if there was any relationship between PMS and arterial hypertension in women, for which one enquired from all female hypertensives attending his private specialist clinic, features consistent with PMS. It is hoped that the findings of this work, preliminary as it would seem, will be capable of shedding some light on this largely uncharted path.

\section{Methodology}

All patients consulting the author in his private specialist clinic for various chronic diseases are given follow-up appointments. This usually ranges from 2 to 12 weeks. It was therefore possible to see all female clients within a 12 week period. Therefore from mid September to mid December, 2004, all female hypertensives consulting the author were asked questions aimed at diagnosing PMS. These were patients whose blood pressures were consistently above 140/90 mm Hg or who were receiving anti-hypertensive medication (without complications like congestive heart failure, cerebrovascular accident and chronic renal failure, or associated diabetes and other endocrinopathies). The interview took place in the clinic setting as part of the consultation encounter, lasting on the average for 20 minutes in each case. Patients were made comfortable as usual and informed that their co-operation would be required in answering questions related to their menstruation; and that they were at liberty to refuse should they feel as such. They were re-assured that refusal to respond would not affect usual care. Informed consent was then requested and given in all instances; and the protocol was approved by the hospital's ethics committee. The University of Carlifornia at San Diego criteria for diagnosis were used. This is one of the criteria recommended by the American College of Obstetrics and Gynaecology [8]. The author put the question thus: "In the last 3 menstrual cycles, do you remember consistently having any of these affective (depression, angry out-burst, irritability, anxiety, confusion, withdrawal) or somatic (breast tenderness, abdominal bloating, headache, leg swelling) symptoms starting about 5 days before menses; and disappearing after menstruation”. This usually came after the routine consultation.

At least one of a group of affective and somatic symptoms over 5 days before menses in three previous cycles is considered diagnostic of PMS. These are expected to disappear after menstruation up till mid cycle.

To serve as control, all females who consulted the author over the same period for minor ailments or chronic diseases without hypertension were asked the same questions after similar explanation and consent request. Data collected included age, presence or absence of PMS, and if hypertensive, state of control.

Controlled blood pressure was taken as blood pressure $<140 / 90 \mathrm{~mm}$ Hg. To avoid memory lapses, information from women who were post menopausal were not analysed.

Since data (except age) were categorical, chi square test was used to determine statistical significance. The level was set at $\mathrm{p}<0.05$.

\section{Results}

There were 88 hypertensives and 33 controls. Of the 88 hypertensives, 40 were menopausal. These were not 
analysed further. The age of the hypertensive pre-menopausal patients ranged from 21 to 51 years; with a mean of $39.8 \pm 1.01$ (SEM). For the control group, the age ranged from 17 to 45 years; with a mean of $31.4 \pm 1.33$ (SEM). Of the 48 pre-menopausal hypertensive women, 31 gave answers diagnostic of PMS while 17 did not. Of the 33 non hypertensive controls, 13 gave answers diagnostic of PMS while 20 did not. Table 1 shows a $2 \times$ 2 contingency table analyzing the difference. It shows that PMS was more frequent to a statistically significant extent in hypertensives compared to controls.

Deriving from the reported experience that control of hypertension was more difficult in hypertensive PMS patients if the PMS was not considered, one decided to see how many of those who despite treatment remained uncontrolled, had PMS. The $2 \times 2$ contingency table of analysis for this is shown in Table 2 . There was a tendency for those with (PMS) to be poorly controlled despite treatment. This however did not reach statistical significance.

\section{Discussion}

Pre-menstrual syndrome is defined as a cyclical disorder involving behavioral, emotional and physical symptoms during the pre-menstrual phase of the menstrual cycle [9]. It is said to affect several women, and is characterized by a cyclic recurrence of symptoms during the luteal phase of the menstrual cycle [10]. In about $2 \%$ $13 \%$, the symptoms are disabling and incapacitating; and in some instances may meet the criteria for diagnosis of pre-menstrual dysphoric disorder (PMDD) [11]. In those with severe symptoms enough to interfere life style and work, the cyclical nature may make it easy to diagnose. In those in whom it is mild however, it may require deliberate focused questioning to unravel it.

This work has shown an association of hypertension with PMS beyond that explainable by chance hence making the hypothesis plausible. We had shown in a different work that though not up to hypertensive levels, the blood pressure of young women significantly rose in the second half of the luteal phase more in those with PMS [12]. This would not be a surprise going by the various aetiological models of PMS. If it is increased perception of mental stress as posited by Rasheed et al. [9], stress by increasing sympathetic autonomic activity can raise blood pressure. The high sympathetic autonomic activity causes increased secretion of aldosterone from the adrenal medulla as well as causing increased production of Angiotensin II by the activated rennin-angiotensin system [13]. If it borders on depression according to Hallman [14], the metabolic consequences therefrom are known to cause a rise in blood pressure [15]. There is hypercortisolaemia in depression [16] which is known to be associated with hypertension, and may be why depression has been found to be predictive of later hypertension [17]. Also sleep quality has been shown to vary with the menstrual cycle, being worse in the second half

Table $1.2 \times 2$ contingency table comparing frequency of presence and absence of P.M.S. among hypertensive pre-menopausal patients and normal controls.

\begin{tabular}{cccc}
\hline & PMS present & PMS absent & Total \\
\hline Hypertensives & 31 & 17 & 48 \\
Normotensives & 13 & 20 & 33 \\
Total & 44 & 37 & 81
\end{tabular}

Chi square $=5.00$, d.f. $=1, \mathrm{p}=0.025$ (statistically significant).

Table 2. A $2 \times 2$ contingency table comparing frequency of control of blood pressure among pre-menstrual hypertensives who had or did not have pre-menstrual syndrome.

\begin{tabular}{cccc} 
& PMS present & PMS absent & Total \\
\hline BP controlled & 12 & 8 & 20 \\
BP uncontrolled & 18 & 9 & 27 \\
Total & 30 & 17 & 47 \\
\hline
\end{tabular}

Chi square $=0.06$, d.f. $=1, p=0.81$ (not statistically significant). 
of the luteal phase, in normal women as well as those with either PMS or the extreme form known as PMDD [18]. This sleep quality disruption is however worse in PMS/PMDD women especially in the second segment of the luteal phase of the menstrual cycle [19]. Disrupted sleep by its effect on the neuroendocrine stress system increases autonomic function and reactivity to stress. Acutely (with each second segment of the menstrual luteal phase) and chronically (with recurrence in each menstrual cycle), this results in several diseases linked with stress; a major one of which is hypertension [20].

The hormonal [21] and fluid retention [22] models, are all capable of initiating and sustaining hypertension. Where a combination of these are at play, it would all go to make the association of PMS and arterial hypertension with this hypothesis more plausible. Initially the blood pressure elevation may be cyclical as the features are confined to the luteal phase of the menstrual cycle. Later it may be possible for the elevation to be sustained through the agency of the kidney. The kidney has been shown to be capable to maintaining apart from generating a hypertensive state [23]. Again the increased blood pressure variability found to be more in the female gender [24] (probably related to changes occasioned by the menstrual cycle) can by increased arterial stiffness and endothelial dysfunction give rise to sustained hypertension [25].

Given the foregoing, it would not be out of place to ascribe a contributory role to PMS in the pathogenesis of arterial hypertension. Where response to regular anti-hypertensive therapy in women is poor, looking for PMS and addressing it both pharmacologically and by life style modification may prove helpful. That means also that just like it is traditional to enquire about oral contraceptive use in females, especially with a history of hypertension; enquiring about features of PMS in females with hypertension should become routine. As a primary prevention, women who show evidence of PMS should be availed of treatment to delay or prevent the development of hypertension. It would appear therefore that from the female gender perspective, PMS could be one of those innovative concepts of hypertension. Innovative concepts in the opinion of Frohlich [26], would improve the understanding and management of the disease.

\section{Conclusion}

This work can at best be considered preliminary, as it is limited by a small sample size. Also its cross-sectional nature means that a cause and effect relationship cannot be conclusively made. A longitudinal prospective follow up study of women with or without PMS to see how more commonly those with PMS develop arterial hypertension in comparison with those without PMS will be more conclusive. That would be the way to go in testing this hypothesis, albeit plausible.

\section{Acknowledgements}

I am grateful to Dr. C. Ogbonna and Mr. Isa Mailafia for helping out with aspects of the statistics.

\section{Conflict of Interest Statement}

There is no financial or personal relationship with any organization that could introduce bias in this work.

\section{References}

[1] Legato, M.J. (2003) Beyond Women's Health: The New Discipline of Gender Specific Medicine. Medical Clinics of North America, 5, 917-937. http://dx.doi.org/10.1016/S0025-7125(03)00063-4

[2] Hanes, D.S., Weir, M.R. and Sowers, J.R. (1996) Gender Considerations in Hypertension Pathophysiology and Treatment. The American Journal of Medicine, 101, 10S-21S.

[3] Kaplan, N.M. (2004) What Can We Expect from New Guidelines? Medical Clinics of North America, 88, $141-148$. http://dx.doi.org/10.1016/S0025-7125(03)00120-2

[4] Savoia, C. and Schiffrin, E.L. (2004) Significance of Recently Identified Peptides in Hypertension: Endothelin, Natriuretic Peptides, Adrenomedulin, Leptin. Medical Clinics of North America, 88, 39-62. http://dx.doi.org/10.1016/S0025-7125(03)00122-6

[5] Johnson, S.R. (1987) Pre-Menstrual Syndrome (Foreword). Clinical Obstetrics and Gynecology, 30, 365-366.

[6] Johnson, S.R. (1987) The Epidemiology and Social Impact of Pre-Menstrual Syndrome. Clinical Obstetrics and Gynecology, 30, 367-376.

[7] Okeahialam, B.N. (2004) Refractory Hypertension Controlled after Identifying and Addressing Pre-Menstrual Syn- 
drome. Journal of the National Medical Association, 96, 1422-1423.

[8] Dickerson, R.M., Mazyck, P.J. and Hunter, M.H. (2003) Pre-Menstrual Syndrome. American Family Physician, 67, 1743-1752.

[9] Rasheed, P. and Al-Sowielem, L.S. (2003) Prevalence and Predictors of Pre-Menstrual Syndrome among College Aged Women in Saudi Arabia. Annals of Saudi Medicine, 23, 381-387.

[10] Daugherty, J.E. (1998) Treatment Strategies for Pre-Menstrual Syndrome. American Family Physician, 58, 183-192, 197-198.

[11] Steiner, M. and Born, L. (2000) Diagnosis and Treatment of Premenstrual Dysphoric Disorder. An Update. International Clinical Psychopharmacology, 15, S5-S17.

[12] Okeahialam, B.N., Obindo, J.T. and Ogbonna, C. (2008) Prevalence of Premenstrual Syndrome and Its Relationship with Blood Pressure in Young Adult Females. African Journal of Medicine Medical Sciences, 37, 361-367.

[13] Kaplan, N.M. (1994) Primary Hypertension. Pathogenesis. In: Kaplan, N.M., Ed., Clinical Hypertension, Wilkins and Wilkins, Baltimore/Philadelphia/Hongkong/London/Munich/Sydney/Tokyo, 47-108.

[14] Hallman, J. (1986) The Premenstrual Syndrome-An Equivalent of Depression? Acta Psychiatrica Scandinavica, 73, 403-411. http://dx.doi.org/10.1111/j.1600-0447.1986.tb02703.x

[15] Saeed, A.K. and Al-Dabbagh, T.Q. (2003) Type 2 Diabetes and Its Association with Hypertension and Depression in an Iraqi Population. Annals of Saudi Medicine, 23, 254-259.

[16] Carpenter, P.C. (1988) Diagnostic Evaluation of Cushings Syndrome. Endocrinology Metabolism Clinics of North America, 17, 445-472.

[17] Jonas, B.S., Fraubs, P. and Ingram, D.D. (1997) Are Symptoms of Anxiety and Depression Risk Factors for Hypertension? Longitudinal Evidence from the National Health and Nutritional Diseases/Epidemiological Follow-Up Study. Archives of Family Medicine, 6, 43-49. http://dx.doi.org/10.1001/archfami.6.1.43

[18] Shechter, A. and Boivin, D.B. (2010) Sleep, Hormones, and Circadian Rhythms throughout the Menstrual Cycle in Healthy Women with Premenstrual Dysphoric Disorder. International Journal of Endocrinology, 2010, Article ID: 259345. http://dx.doi.org/10.1155/2010/259345

[19] Baker, F.C., Kahan, T.L., Trinder, J. and Colrain, I.M. (2007) Sleep Quality and the Sleep Electroencephalogram in Women with Severe Premenstrual Syndrome. Sleep, 30, 1283-1291.

[20] Meelo, P., Sgoifo, A. and Suchecki, D. (2008) Restricted and Disrupted Sleep: Effects on Autonomic Function, Neuroendocrine Stress Systems and Stress Responsivity. Sleep Medicine Reviews, 12, 197-210. http://dx.doi.org/10.1016/j.smrv.2007.07.007

[21] Stickler, R.C. (1987) Endocrine Hypothesis for the Etiology of Premenstrual Syndrome. Clinical Obstetrics \& Gynecology, 30, 377-385. http://dx.doi.org/10.1097/00003081-198706000-00018

[22] Reid, R.L. (1988) Etiology: Medial Models. In: Keye Jr., W.R., Ed., The Pre-Menstrual Syndrome, WB Saunders Co., Philadelphia/Toronto/Montreal/Sydney/Tokyo, 75-77.

[23] Sharma, B.K., Sharma, N. and Jain, S. (1999) Hypertension and the Kidneys: Inter-Relationship and Therapeutic Approach. Journal of Indian Medical Association, 97, 91-105.

[24] Muntner, P., Shimbo, D., Tonelli, M., Reynolds, K., Arnett, D.K. and Oparil, S. (2011) The Relationship between Visit-to-Visit Variability in Systolic Blood Pressure and All-Cause Mortality in the General Population: Findings from NHANES III, 1988-1994. Hypertension, 57, 160-166. http://dx.doi.org/10.1161/HYPERTENSIONAHA.110.162255

[25] Stamatelopoulos, K.S., Georgiopoulos, G., Papaioannou, T., Lambrinoudaki, I., Kouzoupis, A., Vlachopoulos, C., et al. (2012) Can Premenstrual Syndrome Affect Arterial Stiffness or Blood Pressure? Atherosclerosis, 224, 170-176.

[26] Frohlich, E.D. (2004) Innovative Concepts of Hypertension to Understand and Manage the Disease (Preface). Medical Clinics of North America, 88, 13-21. http://dx.doi.org/10.1016/S0025-7125(03)00143-3 
Scientific Research Publishing (SCIRP) is one of the largest Open Access journal publishers. It is currently publishing more than 200 open access, online, peer-reviewed journals covering a wide range of academic disciplines. SCIRP serves the worldwide academic communities and contributes to the progress and application of science with its publication.

Other selected journals from SCIRP are listed as below. Submit your manuscript to us via either submit@scirp.org or Online Submission Portal.
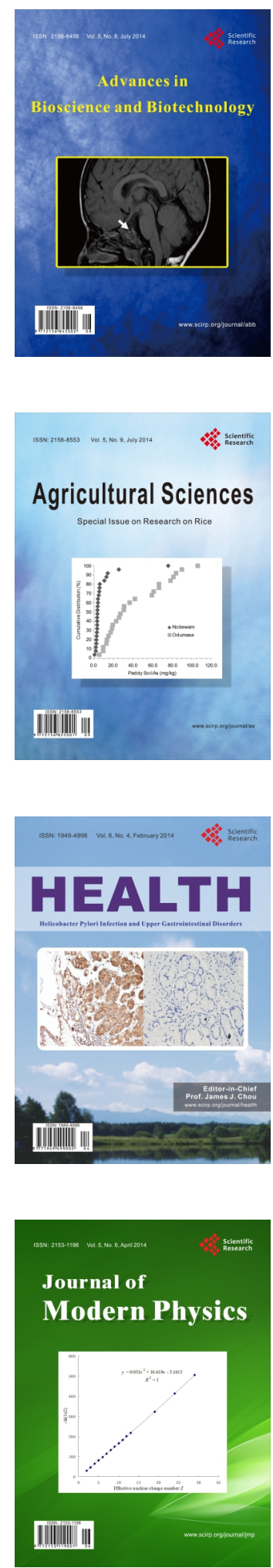
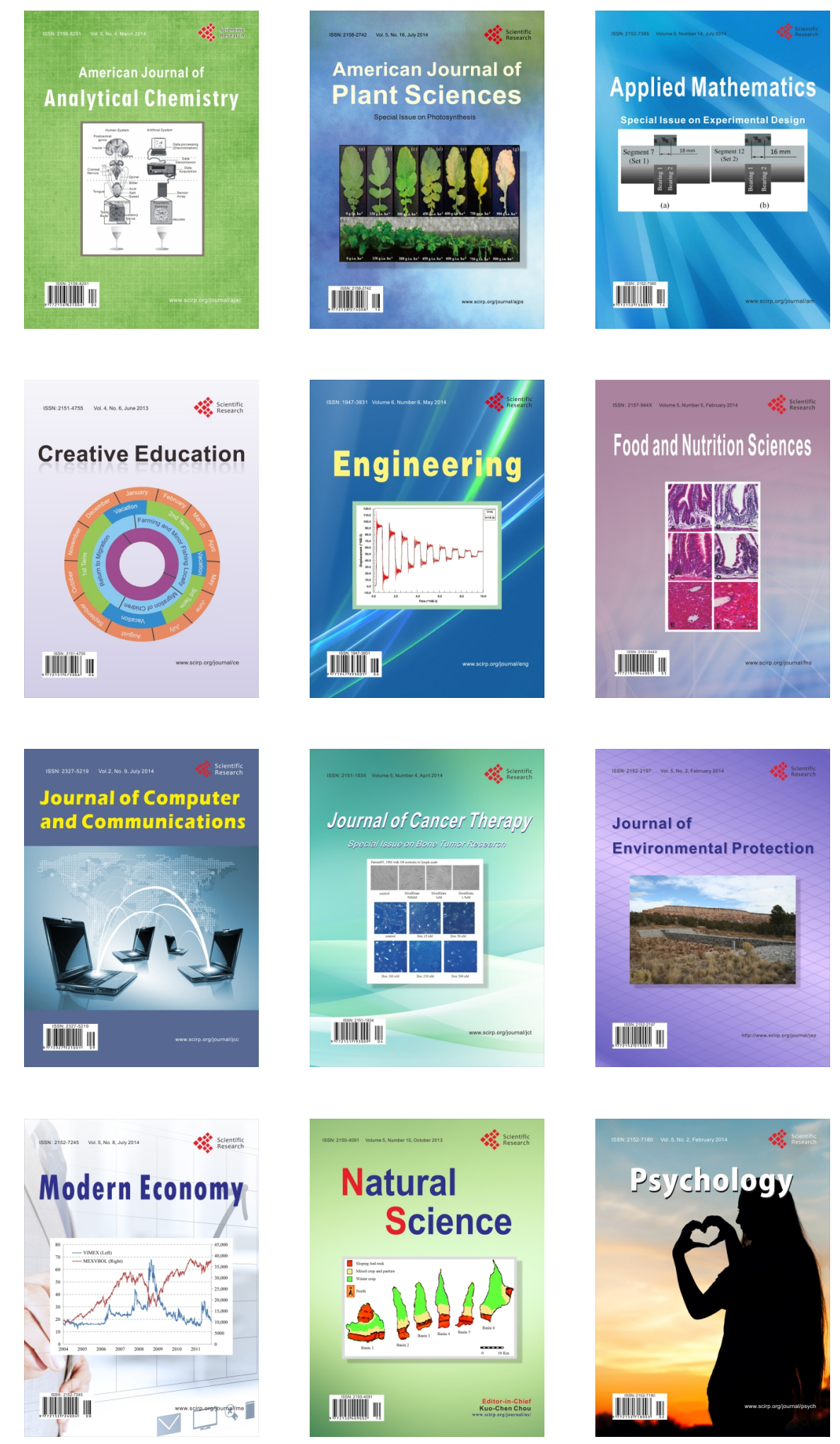